\title{
Frequency and pattern of learner-instructor interaction in an online English language learning environment in Vietnam
}

\author{
Thach Pham \\ Victoria University, Australia \\ Vijay Thalathoti \\ Victoria University, Australia \\ Eva Dakich \\ La Trobe University, Australia
}

\begin{abstract}
This study examines the frequency and pattern of interpersonal interactions between the learners and instructors of an online English language learning course offered at a Vietnamese university. The paper begins with a review of literature on interaction type, pattern and model of interaction followed by a brief description of the online environment and its learners and instructors. The online messages extracted from the communication forums were analysed using simple descriptive statistics and content analysis techniques in the light of Salmon's (2003) model of online teaching and learning to explore the frequency and pattern of interaction. The results of the study indicate that after a high level of engagement at the beginning of the course, the learners' interaction dropped and different patterns interaction were found in the three communication forums of the online course.
\end{abstract}

\section{Introduction}

Computer-mediated communication (CMC) and networked learning have become increasingly popular in education in general and language learning in particular. The integration of CMC into the teaching and learning of languages has proven beneficial to both instructors and learners (Marden \& Herrington, 2011; Son, 2006). Language methodologists have emphasised the important role of interaction in second language acquisition and foreign language learning (Gass \& Mackey, 2006; Long, 2006). In countries where English is a foreign language, creating an online environment for learners to interact with one another, and with the instructors is considered crucial to enhance learners' opportunities to apply what is taught in the classroom settings. However, in order to encourage learners to interact online with peers and instructors in a foreign language, further efforts are needed (Ernest, Heiser, \& Murphy, 2013; Wu, Yen, \& Marek, 2011).

In Vietnam, the setting of this study, language learners have few chances to practice what is taught, especially with native speakers of English. Hence, language teaching institutions have increasingly sought to provide learners with online learning courses so that they can interact with content, peer and instructor - the three main types of interaction (Moore, 1989). Past studies have found that the use of CMC and networked learning can enhance learners' confidence in using English (Liu \& Chen, 2007; Payne \& Ross, 2005). This capability may be particularly important in Vietnam where learners are not proactive in initiating interaction (Le, 2011). In addition, more chances to interact can lead to increased linguistic production (Lee, 2009), and improved social relationships with peers, including native speakers (Belz, 2002). The text-based interaction environment is also less threatening to the learners who are not fluent in speaking, which is the case for many Vietnamese learners of English (Le, 2011).

\section{Type of interaction}

There is a body of empirical research about interaction in online learning. Moore (1989) identified three types of interaction in online environments: learner-content, learner-instructor, and learner-learner. Interaction can occur synchronously (concurrently) using web chat, Skype etc., or asynchronously (not concurrently) using email, forum etc. Studies conducted by Hillman (1994), and Sinha, Khreisat, and Sharma (2009) identified a new dimension of interaction; the learner's interaction with the interface, which looked into learners' interaction with technological tools. Researchers in the field proposed that it was necessary to take into account the role of technologies in the interaction process (Finegold \& Cooke, 2006; Roblyer \& Wiencke, 2003). Learners' familiarity with different functionalities of the interface 
increased their utilisation, and each type of interaction depends on others in online learning environment (Sun \& Hsu, 2013). Among the various types of interaction mentioned above, learner-instructor and learner-learner interactions received a great deal of attention from researchers who focused on different sub-elements of interaction such as engaging learners (Wise, Chang, Duffy, \& Valle, 2004; Yang, 2011), and collaboration for learning (Gallardo del Puerto \& Gamboa, 2009; Kessler \& Bikowski, 2010). These studies investigated, among other things, the role of the instructors, learners' experience with online learning, expectation, satisfaction and the relationship between three key constructs of the Community of Inquiry (COI) model: social, teaching and cognitive presence (Garrison, 2011).

\section{Pattern of interaction}

Another important issue concerning online interaction is the pattern of interaction. In online learning, how do learners and instructors interact with each other? Who starts the interaction process? How do participants maintain interaction throughout the course? These are some of the questions that draw attention from many researchers. For example, Pawan, Paulus, Yalcin, and Chang (2003) and Yang \& Wu (2011) examined how participants initiated, led or maintained interaction threads. They discovered that participants went through different stages of learning; information acquisition, negotiation of meaning, and information contribution. Earlier, Howell-Richardson \& Mellar (1996) explored the dynamics of learners' interaction in two computer mediated communication courses, and reported that learners varied their message length, distribution and links in their interactional acts. Later studies by Zhu (2006), Lally, Lipponen, Simons, and de Laat (2007), and Sun (2011) continued to explore various patterns of interaction between learners and peers, and learners and instructors, as well as learners with content. Like earlier studies, they found a big variation of interaction types: star type of network interaction and interconnected web, as well as different levels of engagement in the beginning, middle and final phrase of study course.

\section{Model of online interaction}

Researchers in the area of online learning proposed a few models to measure quality and/or quantity of online interactions. Built on works of previous researchers, (Angeli, Bonk, \& Hara, 2000; Henri, 1992), Garrison, Anderson and Archer (2001) have created the practical inquiry model with four phases of participation; triggering events, exploration, integration and resolution. Salmon (2003) suggested a similar model with five stages of interaction: stage 1- access and motivation; stage 2- online socialisation; stage 3- information exchange; stage 4- knowledge construction; and stage 5- development. Each of these models used different terms to describe the interaction process, but they both expressed an incremental nature of interaction (from getting to know others to being responsible for one's own learning).

Salmon's model, which serves as the theoretical framework for this study, was developed through the analysis of actual messages and revealed incremental stages of teaching and learning, each of which required different technical and e-moderating skills from moderators (or instructors) and learners. For example, in stage 1, a learner is expected to know how to log on/off the course, how to use different functionalities that the course offers. On the other hand, a moderator, besides being able to log on/off, is expected to send welcoming messages to the learners, and encourage them to start the online learning process. At the highest stage of interactivity, both learner and moderator should be able to support each other, and to provide links outside closed forums. In other words, the teaching and learning process should go beyond the content of the online course.

\section{$\mathrm{CMC}$ and language learning}

CMC technologies have been widely used for the teaching and learning of foreign languages through the utilisation of simple tools such as email, text chat to more complicated learning management systems such as Moodle, WebCT, or customised ones like Tell Me More, Englishtown, Dynamic English (Dyned) or English Discoveries Online (EDO). Interaction in online language learning shares all the above mentioned features of online learning. According to Yang (2011), “a key element in successful language learning through CMC is to engage students in learner-instructor interactions for online learning activities" (p.3). Studies in online interaction in foreign language environments have suggested that CMC provides learners with enjoyable and valuable benefits (Marden \& Herrington, 2011; Son, 2006). 
However, there are still many open questions concerning the use of CMC technologies in foreign language learning, for example, how do students of second/foreign language use online interaction to enhance their language competence? Which mode of interaction is more effective? In what language (native or target) should they use in the interaction process? In addition, it is not yet known whether certain features of interactions in face-to-face mode could be replicated in an online environment (Wanstreet, 2006), nor what are the key factors that may lead to successful online interaction using English; how to link interactions with learning goals (Gibby, 2007; Zhu, 2006); or how to provide language learners with realistic scenarios and suitable non-verbal clues in the interaction process (Tseng, Tsai, \& Chao, 2013).

\section{Methodology}

This study is part of a larger PhD research project investigating learner-instructor interaction in an online language-learning environment at a Vietnamese university. This paper reports on the frequency and pattern of learner -instructor interaction. The specific questions for this study are:

1. What were the frequencies of the learner-learner and learner-instructor interaction?

2. What were the patterns of the interaction?

The research utilised an explanatory design (Creswell, 2013), which investigated different aspects of learner -instructor interaction in the course. The following part of the paper presents the data collection and analysis process, followed by a description of the online environment, especially its communication forums. Participants of the study are briefly described at the end of this section.

\section{Data collection and analysis}

This study examined online messages from three asynchronous CMC forums of an online English language course at a university in Vietnam. The first message occurred in late October, 2011 and the last one was found in late May, 2012. Scripts of the learners' and instructors' online interaction process were extracted through the Teacher Management System (TMS) of the course.

The data were analysed using both simple descriptive statistics (Byrne, 2002) such as frequency analysis, and content analysis (Miles, Huberman, \& Saldaña, 2014). Within frequency analysis, the study focused on comparing number of posts in the three communication forums, a longitudinal investigation of the number of posts (number of posts each month), and response time between sent and received dates of the posts. The unit of content analysis of the posts was single post from both the learners and instructors to explore emerging patterns of the interaction threads. The researchers of this study applied Salmon's (2003) model of teaching and learning through online discussion groups to examine which stage these posts could achieve.

\section{The online environment}

The online course selected in this study was English Discoveries Online (EDO). It included different components for the learners to interact with content, and tools to communicate with their peers and instructors. In this study, the exchange of online messages between the learners and instructors were extracted from the three interaction forums. They were: (i) the Support tool for learner-to-instructor interaction only, (ii) the Class Discussion for the learners and instructors of a particular group, and (iii) the Community Discussion for all the users of the online course both in Vietnam and other countries. The main difference among the three forums was in the extent to which the learners could see and interact with others. In the Support tool, the learners could read and reply their instructor's messages but were unable to see their peers' posts. The peer posts were, however, visible in the Class Discussion. In the Community Discussion, the learners could interact with all other users of the online course, including their instructors, from Vietnam and other countries. 


\section{Participants}

The participants for this study were the learners and instructors of an undergraduate course majoring in English of a Vietnamese university. They had face-to-face English lessons four times a week and were given access for online study at their own time. There were 252 learners in 10 groups that were supervised online by five instructors. In early October 2011, the learners had a hands-on orientation session in which they were given step-by-step instruction on how to use the course. There was also a regulation from the university stating that they had to complete $80 \%$ of the assigned materials (content) to be eligible to sit for the term test. The built-in Teacher Management System (TMS) enabled the instructors to track how much a learner had completed the assigned study level(s). The instructors were among the lecturers of the same university. They taught these students in the face-to-face lessons, and were also assigned to supervise the learners' online study. Their duties included assigning homework to the learners, answering their queries, creating discussion topics, and reminding the learners to meet the study deadline. Each instructor was asked to supervise two groups with a total of about 50 learners.

\section{Results}

The following section presents the results of the study. It is divided into two main sub-headings: frequency and pattern of interaction.

\section{Frequency of interaction}

One of the issues in online interaction that was studied a great deal was that of frequency. In this study the researchers explored three issues: number of posts, sent and received time, and the time gaps between the sent and received messages in the communication forums.

\section{Number of posts from learners and instructors}

The largest number of posts was seen in the learner-to-instructor interaction forum (Support) with 209 posts from 95 learners. This was followed by posts in the Community Discussion: 113 posts from 27 learners. The smallest number was found in the Class Discussion: 78 posts from 35 learners. The above figures translate into the same average number of 0.08 posts per learner in the Support and Class Discussion forums and 0.15 posts per learner in the Community Discussion forum per week.

All five instructors of the course posted messages in the Support and Class Discussion, but none of them took part in the Community Discussion forum. The number of posts found in the Support and Class Discussion forums was 159 and 95 respectively. However, the majority of the posts in the latter forum were the topics that the instructors assigned to their respective groups. The above figures translate into the average numbers of 1.4 and 0.7 posts per instructor per week in the Support and Class Discussion.

\section{Sent-received time of the posts}

There was a chronological consistency in the time when posts were sent and received in the three communication forums. The data showed that after a slow start, because the learners were not given access to the online course until the middle of October 2011, their participation increased sharply from November until the middle of December. However, this momentum fell sharply afterwards and stayed low for the next three months. In fact, their participation in the Community Discussion almost came to halt after January 2012. The intensity of interaction only rose slightly in April and May when the learners' academic year was about to end (see Figure 1). 


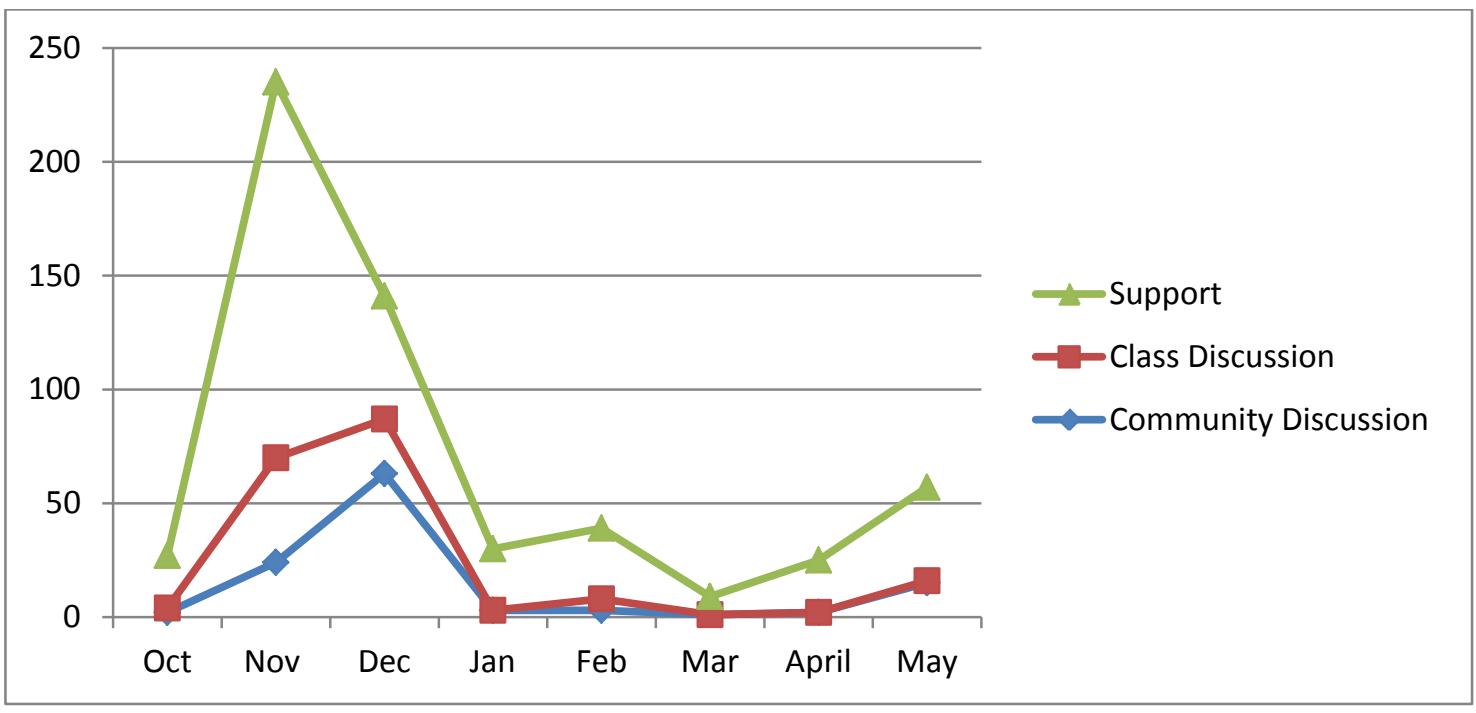

Figure 1. Time of the posts in three communication forums

\section{Response time}

The current study only explored the response time between sent and received dates of the posts in the learner-to-instructor communication space (Support). The majority of messages (72\%) were replied within 1 to 5 days. There were a few cases when questions from the learners were responded on the same day. However, there were also instances when the response time was very long (more than a month). This was because of the periods of national and traditional New Year holidays or term break. The learning management system did not allow the learners to forward their messages to instructors' external email addresses, hence the instructors only knew about these messages when they logged in to the course.

In summary, the learners' participation with their peers and instructors was different in each of the three CMC forums. After a relatively active initial period of posting in the discussions, the learners lost their interest in communicating with others. In the later period of study, the learners only maintained some interaction with the instructors to report their study progress or technical problems. It took the instructors of current study longer time to reply to their learners' messages compared with the average length of three days in literature of Mazzolini and Maddison (2007), Hew and Cheung (2008), and Chang, Chen, and Hsu (2011).

In order to understand more about the learners' and instructors' actual behaviour during the interaction process, the researchers conducted content analysis of their posts, using each message as a unit of analysis (Lee, 2012; Mazzolini \& Maddison, 2003, 2007). This qualitative analysis of the posts aimed to examine the pattern of the interaction.

\section{Pattern of interaction}

The learners of the present study varied their pattern of interaction depending on which forum they took part in. The following part presents key interaction patterns that could be identified. They were instructorinitiated, learner-initiated, one-way, two-way and multi-direction.

\section{Instructor-initiated interaction}

This pattern of interaction occurred mainly in the Support forum. Due to the set-up of this communication space, interaction was only possible between an instructor and one or more learners within the same group. Based on the messages extracted from the system, the following pattern could be drawn: 


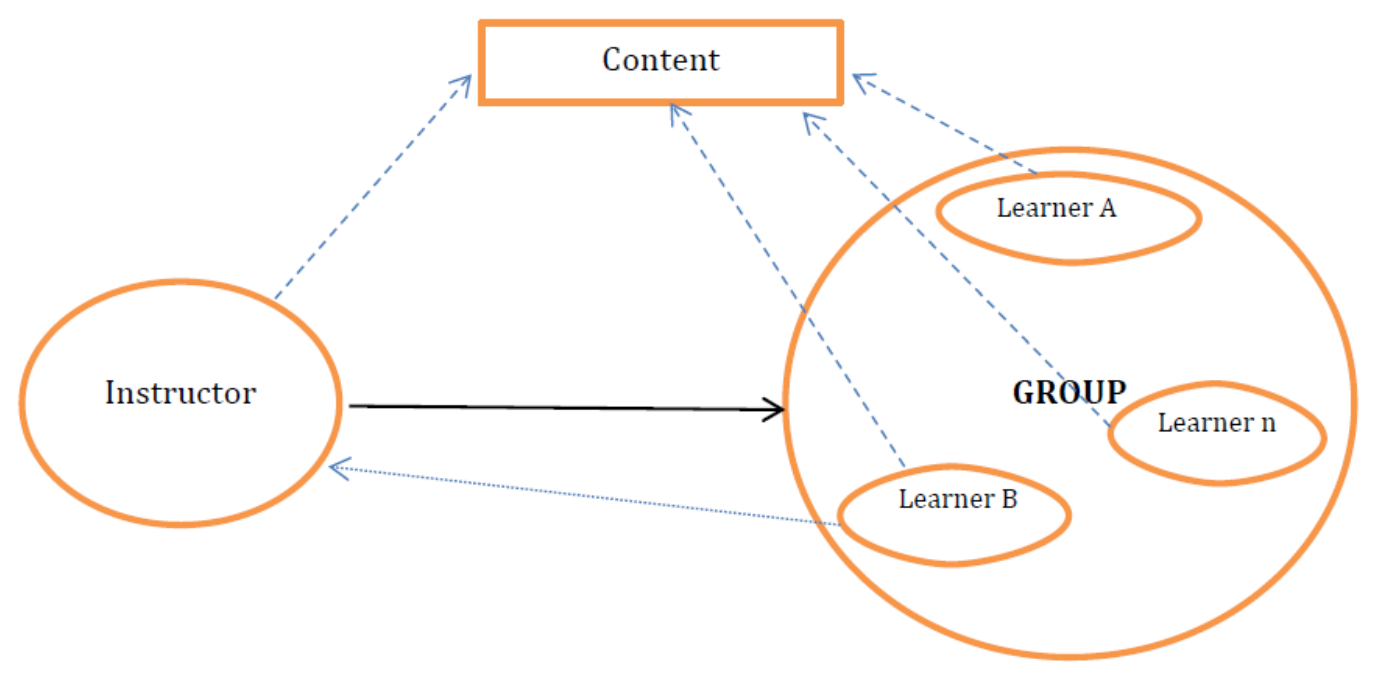

Figure 2. Instructor-initiated pattern of interaction in Support forum

In this communication forum, the intermediary point of contact was the content of the online course. Quantitative analysis of online messages showed that while some learners were active in doing exercises of the course, others were not. Therefore the instructors had to send out messages to all learners reminding them of the need to complete the assigned tasks. After receiving such messages (solid arrow), individual learners started to interact with content (dashed arrow) and fulfil the assignments. Some of them then composed a message and sent it to the instructor (dotted arrow) reporting their study progress or technical problems. Interestingly, not all the learners replied to their respective instructors' messages.

The instructor-initiated pattern of interaction also occurred in the Class Discussion forum. Due to the setup of this forum, the interaction had to start from the instructor who created a topic and encouraged the learners to take part in the discussions. When a learner did so, his/her post was seen by all other learners of the group and the instructor. Then the learner(s) started to post their ideas on the topic and/or responded to opinions from the peers. The evidence from the posts showed that most of the reflective posts were from the learners. The instructor's engagement was limited to assigning topics to the groups of learners under their supervision. The learners' level of participation in this forum varied from class to class (group). For example, in one of the groups, only four topics were assigned, but learners posted 37 messages. On the other hand, another group was assigned with 62 topics, and only one comment was made by a learner.

\section{Learner-initiated interaction}

The analysis of the online messages revealed that the learners also started the interaction process. This occurred primarily in the Community Discussion forum where the learners could diversify their interaction, i.e. they communicated with anyone who had access to the online course. The researchers browsed all eight topics in this communication forum and picked up the users who were the participants of this study (identifiable through account configuration). Their engagement was calculated and analysed to see if they were initiators or commentators, and who they were interacting with.

From the online messages, it can be seen that the learners played the roles of both initiator and commentator of the posts but the latter accounted for a much higher proportion: $79 \%$ versus $21 \%$. They interacted more with foreigners than with Vietnamese: $43 \%$ versus $29 \%$. Out of 27 learners participating in the Community Discussion forum, the majority (74\%) contributed from one to three posts; $20 \%$ posted four to nine messages. One participant wrote as many as 47 posts (42\%) in six topics. When a learner initiated a new discussion, he or she triggered an interaction process which resulted in multi-directional communication. 


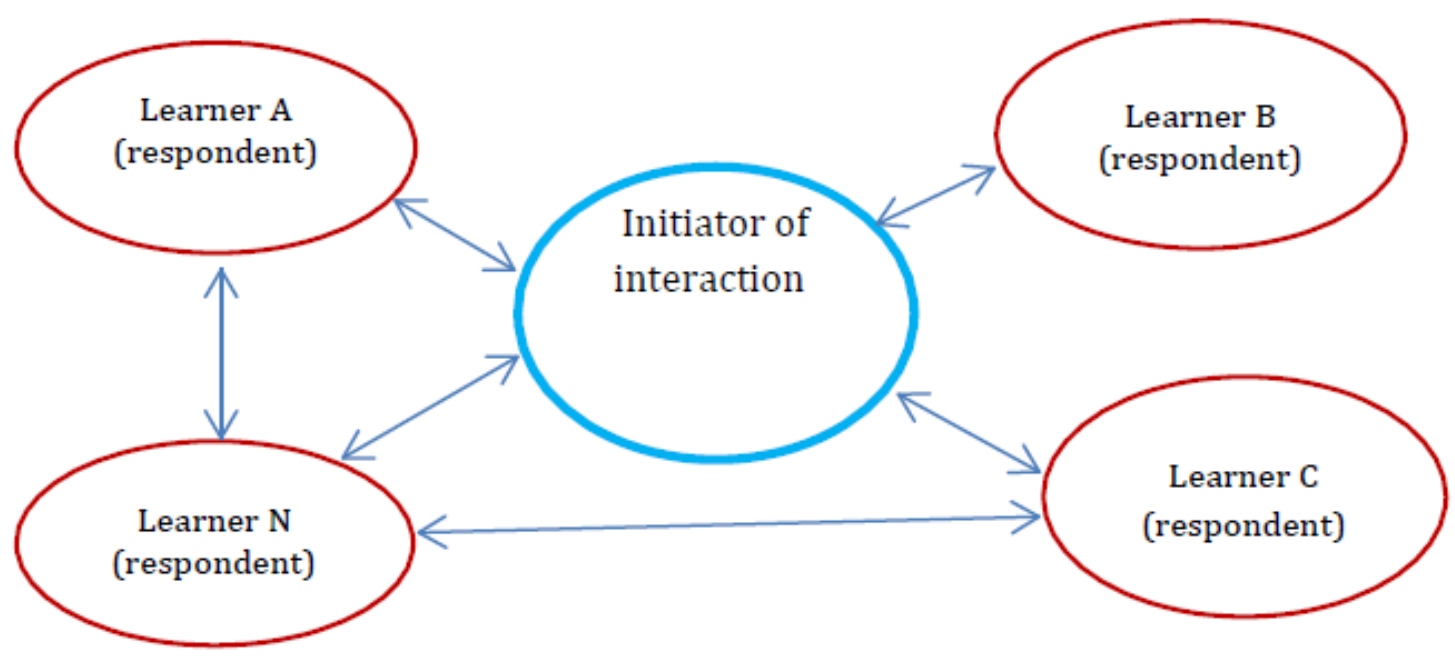

Figure 3. Learner-initiated pattern of interaction

From the data in the above figure, it is apparent that when a learner posted a message, he or she could be responded to by a number of other users of the online course. This in turn triggered interaction among themselves (e.g. learner $\mathrm{C}$ and $\mathrm{N}$ ).

One-way interaction

There were a number of occasions in which the interaction was one-way. For example, when an instructor provided information to the whole group and no learners responded - as occurred when all the instructors sent their learners an announcement about an online contest during February 2012. The data extracted from the TMS also revealed that nearly $30 \%$ of the learners' questions sent to instructors went unanswered. Similarly the learners' submission of assignments did not always elicit comments from instructors or peers.

Two-way interaction

Two-way interactions occurred between the learners and instructors and between two or more learners. A two-way interaction occurred when a learner sent a question or information to the instructor and received a response. On a few occasions this resulted in several rounds of interaction back and forth between individual learners and instructors. Two-way patterns of interaction also occurred in the Community Discussion forum between the initiator of a message and only one participant, as seen in Figure 4 below.

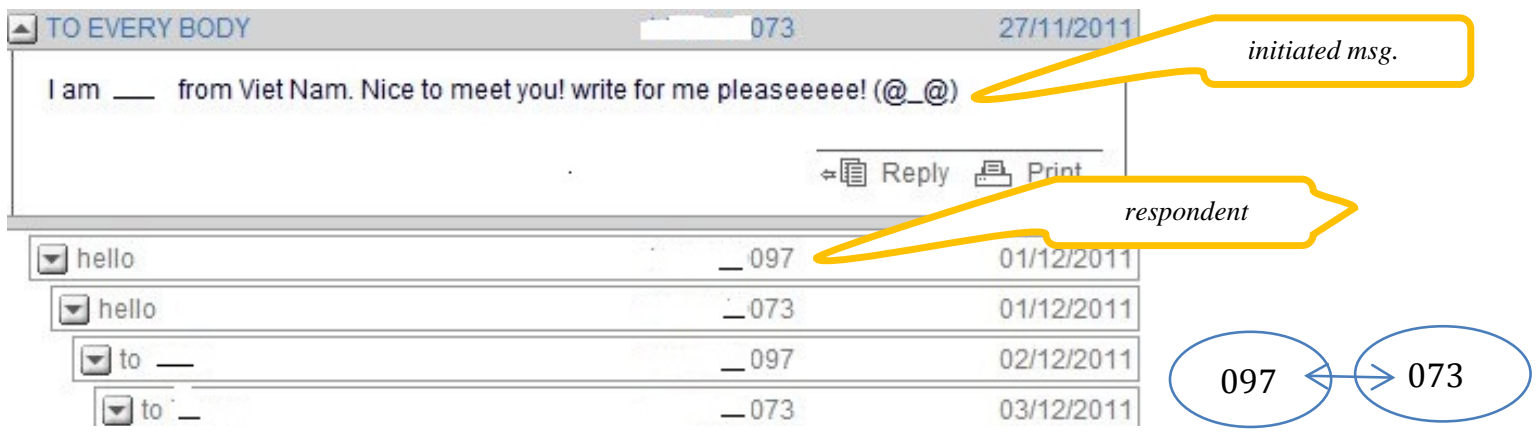

Figure 4. Two-way interaction

The above Figure shows a two-way interaction between an initiator (ID 073) and one respondent (ID 097). More specifically, on November 27th, 2011 learner ID 073 sent out a general message to all other users of the Community Discussion. Four days later, the initiator received a response from one learner (ID 097). These two learners continued their interaction for a few days later, until 3rd December. 
Multi-directional interaction

In the Community Discussion forum there were a few occasions in which more than two participants took part in the discussion, as shown in Figure 5.

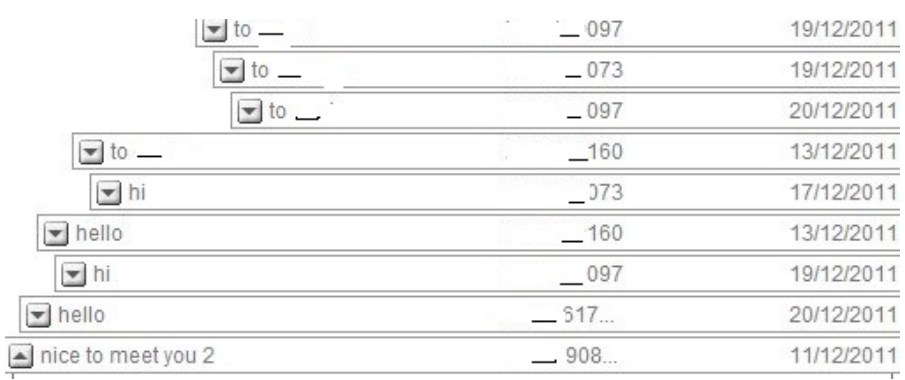

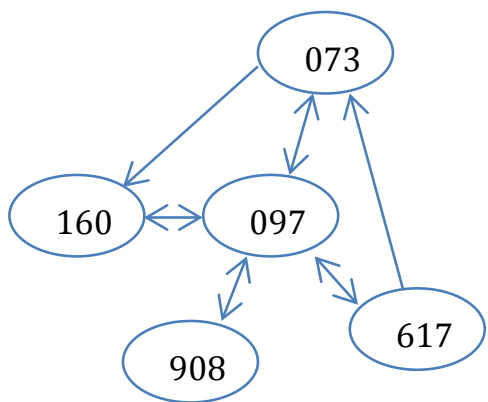

Figure 5. Multi-directional interaction

From the above figure we can see that several learners took part in the discussion that was initiated by one of the learners (ID 097). While two learners (ID 097 and 073) were chatting, another learner (ID 160) jumped in to respond to the original message (I'm ... from Vietnam. Nice to meet you! Write for me please). This was responded by the initiator of the message (ID 073). Afterwards, the interaction involved the learners from other countries (ID 617 and 908). It was observed that learner ID 097 was the centre of the discussion, and that not all participants were connected.

In summary, online messages from three communication forums revealed that interactions could start either from the instructors or learners. Interaction could also be one-way, two-way or multi-directional. The patterns varied with the instructor-initiated interactions occurring more often in the Support and Class Discussion forums, and more learner-initiated interactions in the Community Discussion space.

\section{Discussion}

The two issues that this study aimed to explore were: frequency and pattern of interaction between learners and instructors in an online course at a Vietnamese university. These issues will now be discussed in more detail, followed by suggestions for future studies.

\section{Frequency of interaction}

From the number of posts in the three communication forums of this online course, two main observations could be made. Firstly, the learners participated in the discussion at different frequencies in the different communication forums. Secondly, the number of posts per learner in this course was quite low. Although it is difficult to make accurate comparison with other studies because of different contexts involved, results of some published research showed much higher averages. For example, study by Hara, Bonk, and Angeli (2000) reported an average of one post per student per week. Similarly, Schellens and Valcke (2005) found that each learner in their study posted 1.48 messages per week. A higher average of 3.36 messages per student per week was seen in Lee's study (2012). In this online course, an average of only 0.1 message per learner per week were yielded. This finding is very disappointing.

Regarding the average number of posts per instructor, the results of this study show that the instructors also participated at different frequencies in the different communication forums. This finding is in agreement with the result of study by Pawan et al. (2003) whereby there was an uneven instructor participation among three communication forums of the online course. Although the average number of of posts per instructor was much higher than the learners', they were incomparable with results of some published studies by Sing \& Khine (2006) and Hara et al. (2000) with the averages of 2.33 and 2.1 respectively. This result is also rather disappointing.

A possible explanation for this might be that participation was not compulsory. These learners had just left school environment where they had been used to being told what to do (Le, 2011). They may not be 
autonomous enough, and thus when they were allowed to be on their own, they would not study online voluntarily. The learners may not take responsibility if they feel that they have no obligation to post or to read peer's post (Donald, 1996). Furthermore there was no explicit link between their participation in the communication forums and their learning goals, especially in the Community Discussion. At the end of the study terms these learners had to take the tests in listening, speaking, reading and writing in English, while the posts in these discussions were mainly the short, simple written ones with no or little linguistic correction from the peers or instructors.

The time gap between sent and received posts is not comparable with other studies either. Ideally all questions from learners should be answered within two weeks (Mazzolini \& Maddison, 2007) although an average response time of two to three days would be more acceptable to learners (Hew \& Cheung, 2008). However, in order to meet these targets, a dedicated assistant is needed to respond to students queries for several hours per week (Chang, Chen, \& Hsu, 2011). No such assistance was available in the present study and given the numbers of learners involved (more than 50 learners per supervisor), it was not possible for the instructors to be available on demand. It is also worth noting that learners and instructors of this study met face-to-face every week, which provided the learners with a regular opportunity to have their questions answered offline.

From the study results, it was possible to suggest that the majority of the online messages in the communication forums of this online course only centred on stages two and three of Salmon's model (online socialisation and information exchange). Indeed the learners neither showed much interest in getting comments from others nor gave their opinions on the peers' posts. It seems that the learners and instructors of this course thought that it was sufficient to send information (through announcements, assignments) to others. However it is argued by some researchers (Kim, 2008; Lee, 2012) that this 'monologue' type of interaction cannot result in deep and meaningful interaction.

\section{Pattern of interaction}

The results of this study show a considerable variation in the pattern of interaction between the learners and instructors as well as among the learners. This was partly due to the architecture of the communication forums and the cultural characteristics of the participants.

The instructor-initiated pattern of interaction mainly occurred in the Support and Class Discussion forums where the instructors sent out announcements and assigned different topics for discussions. The instructors' messages and assigned topics served as constant reminders to the learners the need to interact with the course content, with one another to improve their English and/or learn from external sources. This started the online learning process for the learners through doing exercises in listening, speaking, reading etc., and/or submission of written homework or participation in the discussions in the target language (English). This finding supports previous studies into the patterns of learner-instructor interaction (Pawan et al., 2003; Sun, 2011).

However, as discussed above, it was observed that the instructors' provision of information (announcements) and monologue nature of the learners' assignments mostly resulted in one-way communication. There are several possible explanations for this result. Firstly, answering to the instructors' messages and commenting on peers' posts was not compulsory in this online course, and not all posts necessarily required a response. The primary purpose of some posts was to convey some simple fact or information (e.g. instructions or reminders), and as long as the learners understood the post, there might have been no real reason for them to respond. Secondly, the instructors and learners also met faceto-face, so they might have discussed the messages or posts directly in the class. Thirdly, because of Confucian culture, the learners neither wanted to challenge the instructors' message nor criticise peers' posts.

The learner-initiated interactions, which occurred mainly in the Community Discussion, provided a good environment for the learners to apply what they had learnt from the course content, and classroom context. The interaction in this forum was topic-based, but the learners were free to post on any issue in English. Furthermore, having chances to interact with the learners from other countries was a good catalyst for the Vietnamese learners to enhance their English, and communication skills. This is considered to be a valuable resource for these learners because of the limited opportunities to practice 
English outside the classroom context (Le, 2011). However, most of the posts by the learners of this study were still short, and interaction mainly stalled at the socialisation stage (Salmon, 2003). Although this was good for the learners to make friends with peers from other groups and other countries, it was not sufficient for them to make online interaction truly meaningful, especially for learning English. There was also a lack of structured discussion thread and the leadership from the initiator(s). Consequently, it did not result in cognitive presence or quality discussion as suggested in past studies (Garrison \& ClevelandInnes, 2005; Zhu, 2006).

\section{Conclusion and recommendation for further studies}

This study examined interpersonal communication between the learners and instructors in an online course at a university in Vietnam. The results indicated that there was a difference in the frequency and pattern of interaction in the three communication forums by both the learners and instructors. The use of Salmon's (2003) model of teaching and learning enabled the researchers to measure quantitatively and qualitatively the learners' and instructor's engagement in the interaction process. Although the study only investigated online messages that were found in the communication forums of the online course, it could draw some interesting findings that were worth in-depth investigation in future studies.

Firstly, the three communication forums of the online course provided the learners with a useful platform to enhance their communication skills (in English) with peers and instructors. This is useful in the context that there are not many chances for Vietnamese learners to practice English because of the status of the English as a foreign language in the country. This was supported by the fact that the learners of this study were eager to take part in the online interactions at the start of the course, and that their interactions were directed toward different people: instructors, Vietnamese and international peers. Unfortunately, they lost their momentum in the later stage of their online learning. Possible explanations to this were that participation was not compulsory, and that the learners did not see the linkage between the participation and their learning goals. Interviews with the learners may be useful to explore how to maintain interaction throughout an online course; and how to match online discussions with learning needs.

Secondly, content analysis of the learners' posts in the communication forums revealed that their cognitive presence was varied. It was highly present in the assignments that the learners sent to their instructors, and in some instances, their comments to the peers' posts. Their high cognitive presence showed that these learners invested time to read, think and compose pieces of writing in English. The online environment gave the learners, especially the shy ones, a good chance to express their thoughts, opinions etc. Nevertheless, in the dialogues with their peers, the learners of this study did not show high level of cognitive presence. Most of their messages stalled at getting to know about peers with simple English expressions. More structured dialogues would have been instrumental to further their conversations, and better their English accordingly. It is a matter for future investigation to understand how online interaction in English should be organised for optimal benefits to the learners.

Finally, the results of the present study indicated that the instructors' engagement in the interaction process was varied. They paid a great deal of attention to guiding and motivating the learners to interact with one another and with content, but they did not intervene in the learners' interaction with peers. They might have been too busy, or they might have thought that it would be better for the learners to interact among themselves without being watched by the instructors. This was possibly because of the cultural reason. In Vietnam, learners are often reluctant to chat frankly at the presence of teachers, both physically and virtually. Unlike in western culture, the mode of addressing teachers in Vietnamese language (Thua cô/Thura thầy = Dear Mr/Miss Teacher) makes the social connectedness between learners and instructors less easy to establish. Future research might explore views of both learners and instructors about appropriate level of instructor's participation (socially and academically) to boost learning outcomes (cognitive presence) in an online English language learning environment.

\section{Limitations}

The findings in this study are subject to at least three limitations. Firstly, different communication forums of this online course had different objectives. Hence, caution should be taken into consideration before a conclusion could be made with regards to the learners' and instructors' participation. Secondly, the classification of the message content could be subjective, so it would be necessary to have measures to 
ensure reliability of data coding (Johnson \& Christensen, 2012). Thirdly, the study relied on only one set of data, i.e. the messages found in the three communication forums of the online course, which did not reflect all interpersonal interaction types like email, phone, face-to-face etc., and interaction with the content. Hence, it would not be possible to draw a definite conclusion about the course design or effectiveness of online discussion (Ng \& Murphy, 2005). Therefore future research should include surveys, interviews and observation to obtain a fuller picture of learner-learner, learner-instructor and learner-content interaction in an online English language learning course.

\section{Acknowledgements}

The researchers would like to thank Australian Government for financial support and the staff and students of the participating university for taking part in this study.

\section{References}

Angeli, C., Bonk, C. J., \& Hara, N. (2000). Content analysis of online discussion in an applied educational psychology course. Instructional Science, 28(2), 115-152.

Belz, J. A. (2002). Social dimensions of telecollaborative foreign language study. Language Learning \& Technology, 6(1), 60-81. Retrieved from http://ltt.msu.edu/vol6num1/default.html

Byrne, D. S. (2002). Interpreting quantitative data. London: SAGE.

Chang, C.-K., Chen, G.-D., \& Hsu, C.-K. (2011). Providing adequate interactions in online discussion forums using few teaching assistants. Turkish Online Journal of Educational Technology, 10(3), 193-202.

Creswell, J. W. (2013). Research design: Qualitative, quantitative, and mixed methods approaches. Thousand Oaks, CA: SAGE.

Donald, E. M. (1996). A Content Analysis of Student/Instructor Communication via Computer Conferencing. Higher Education, 32(2), 217-241.

Ernest, P., Heiser, S., \& Murphy, L. (2013). Developing teacher skills to support collaborative online language learning. The Language Learning Journal, 41(1), 37-54.

Finegold, A. R. D., \& Cooke, L. (2006). Exploring the attitudes, experiences and dynamics of interaction in online groups. Internet and Higher Education, 9(3), 201-215.

Gallardo del Puerto, F., \& Gamboa, E. (2009). The evaluation of computer-mediated technology by second language teachers: Collaboration and interaction in CALL. Educational Media International, 46(2), 137-152.

Garrison, D. R. (2011). E-learning in the 21st century: A framework for research and practice. NY: Taylor \& Francis.

Garrison, D. R., Anderson, T., \& Archer, W. (2001). Critical thinking, cognitive presence, and computer conferencing in distance education. The American Journal of Distance Education, 15(1), 7-23.

Garrison, D. R., \& Cleveland-Innes, M. (2005). Facilitating cognitive presence in online learning: Interaction is not enough. The American Journal of Distance Education, 19(3), 133-148.

Gass, S. M., \& Mackey, A. (2006). Input, interaction and output: An overview. AILA Review, 19(1), 3-17.

Gibby, A. S. (2007). Student perceptions of interaction in an online foreign language learning environment. (Doctoral dissertation, University of Texas at Austin, USA). Retrieved from http://repositories.lib.utexas.edu/handle/2152/3219

Hara, N., Bonk, C. J., \& Angeli, C. (2000). Content analysis of online discussion in an applied educational psychology course. Instructional Science, 28(2), 115-152.

Henri, F. (1992). Computer conferencing and content analysis. In A. R. Kaye (Ed.), Collaborative learning through computer conferencing (pp. 117-136). Heidelberg, VIC: Springer.

Hew, K. F., \& Cheung, W. S. (2008). Attracting student participation in asynchronous online discussions: A case study of peer facilitation. Computers \& Education, 51(3), 1111-1124.

Hillman, D. C. A. (1994). Learner-interface interaction in distance education: An extension of contemporary models and strategies for practitioners. The American Journal of Distance Education, 8(2), 30-42.

Howell-Richardson, C., \& Mellar, H. (1996). A methodology for the analysis of patterns of participation within computer mediated communication courses. Instructional Science, 24(1), 47-69.

Johnson, B., \& Christensen, L. B. (2012). Educational research: Quantitative, qualitative, and mixed approaches. Thousand Oaks, CA: SAGE. 
Kessler, G., \& Bikowski, D. (2010). Developing collaborative autonomous learning abilities in computer mediated language learning: Attention to meaning among students in wiki space. Computer Assisted Language Learning, 23(1), 41-58.

Kim, H. N. (2008). The phenomenon of blogs and theoretical model of blog use in educational contexts. Computers \& Education, 51(3), 1342-1352.

Lally, V., Lipponen, L., Simons, R.-J., \& de Laat, M. (2007). Investigating patterns of interaction in networked learning and computer-supported collaborative learning: A role for social network analysis. International Journal of Computer-Supported Collaborative Learning, 2(1), 87-103.

Le, S. T. (2011). Teaching English in Vietnam: Improving the provision in the private sector. (Doctoral dissertation, Victoria University, Melbourne, Australia). Retrieved from http://library.vu.edu.au/record=b2237480

Lee, J.-Y. (2009). The effect of computer-mediated communication (CMC) interaction on L2 vocabulary acquisition: A comparison study of CMC interaction and face-to-face interaction. (Master thesis, Iowa State University). Retrieved from http://lib.dr.iastate.edu/cgi/viewcontent.cgi?article=1802\&context=etd

Lee, J. (2012). Patterns of interaction and participation in a large online course: Strategies for fostering sustainable discussion. Educational Technology \& Society, 15(1), 260-272.

Liu, G. Z., \& Chen, A. S. W. (2007). A taxonomy of internet-based technologies integrated in language curricula. British Journal of Educational Technology, 38(5), 934-938.

Long, M. H. (2006). Input, interaction, and second language acquisition. Annals of the New York Academy of Sciences, 379(1), 259-278. Retrieved from http://onlinelibrary.wiley.com/doi/10.1111/j.1749-6632.1981.tb42014.x/pdf

Marden, P. M., \& Herrington, J. (2011). Supporting interaction and collaboration in the language classroom through computer mediated communication. Paper presented at the World Conference on Educational Multimedia, Hypermedia and Telecommunications, Lisbon, Portugal. Retrieved from http://researchrepository.murdoch.edu.au/6974/

Mazzolini, M., \& Maddison, S. (2003). Sage, guide or ghost? The effect of instructor intervention on student participation in online discussion forums. Computers \& Education, 40(3), 237-253.

Mazzolini, M., \& Maddison, S. (2007). When to jump in: The role of the instructor in online discussion forums. Computers \& Education, 49(2), 193-213.

Miles, M. B., Huberman, A. M., \& Saldaña, J. (2014). Qualitative data analysis: A methods sourcebook. Thousand Oaks, CA: SAGE.

Moore, M. G. (1989). Editorial: Three types of interaction. The American Journal of Distance Education, 3(2), 1-7.

Ng, K. C., \& Murphy, D. (2005). Evaluating interactivity and learning in computer conferencing using content analysis techniques. Distance Education, 26(1), 89-109.

Pawan, F., Paulus, T. M., Yalcin, S., \& Chang, C. F. (2003). Online learning: Patterns of engagement and interaction among in-service teachers. Language Learning \& Technology, 7(3), 119-140.

Payne, J. S., \& Ross, B. M. (2005). Synchronous CMC, working memory, and L2 oral proficiency development. Language Learning \& Technology, 9(3), 35-54.

Roblyer, M., \& Wiencke, W. (2003). Design and use of a rubric to assess and encourage interactive qualities in distance courses. The American Journal of Distance Education, 17(2), 77-98.

Salmon, G. (2003). E-moderating: The key to teaching and learning online. London, England: RoutledgeFalmer.

Schellens, T., \& Valcke, M. (2005). Collaborative learning in asynchronous discussion groups: What about the impact on cognitive processing? Computers in Human Behavior, 21(6), 957-975.

Sing, C. C., \& Khine, M. S. (2006). An analysis of interaction and participation patterns in online community. Journal of Educational Technology \& Society, 9(1), 250-261.

Sinha, N., Khreisat, L., \& Sharma, K. (2009). Learner-interface interaction for technology-enhanced active learning. Innovate: Journal of Online Education, 5(3), 1-7.

Son, J.-B. (2006). Using online discussion groups in a call teacher training course. Regional Language Centre Journal, 37(1), 123-135.

Sun, J.-n., \& Hsu, Y.-c. (2013). Effect of interactivity on learner perceptions in Web-based instruction. Computers in Human Behavior, 29(1), 171-184.

Sun, S. Y. H. (2011). Online language teaching: The pedagogical challenges. Knowledge Management \& E-Learning: An International Journal, 3(3), 428-447.

Tseng, J.-J., Tsai, Y.-H., \& Chao, R.-C. (2013). Enhancing L2 interaction in avatar-based virtual worlds: Student teachers' perceptions. Australasian Journal of Educational Technology, 29(3), 357-371. 
Wanstreet, C. E. (2006). Interaction in Online Learning Environments: A Review of the Literature. Quarterly Review of Distance Education, 7(4), 399-411.

Wise, A., Chang, J., Duffy, T., \& Valle, R. (2004). The effects of teacher social presence on student satisfaction, engagement, and learning. Journal of Educational Computing Research, 31(3), $247-$ 271.

Wu, W.-c. V., Yen, L. L., \& Marek, M. (2011). Using online EFL interaction to increase confidence, motivation, and ability. Journal of Educational Technology \& Society, 14(3), 118-129.

Yang, Y.-F., \& Wu, S.-P. (2011). A collective case study of online interaction patterns in text revisions. Educational Technology \& Society, 14(2), 1-15.

Yang, Y. F. (2011). Engaging students in an online situated language learning environment. Computer Assisted Language Learning, 24(2), 181-198.

Zhu, E. (2006). Interaction and cognitive engagement: An analysis of four asynchronous online discussions. Instructional Science, 34(6), 451-480.

Corresponding author: Thach Pham, thach.pham@live.vu.edu.au

Australasian Journal of Educational Technology (C) 2014.

Please cite as: Pham, T., Thalathoti, V., \& Dakich, E. (2014). Frequency and pattern of learner-instructor interaction in an online English language learning environment in Vietnam. Australasian Journal of Educational Technology, 30(6), 686-698. 